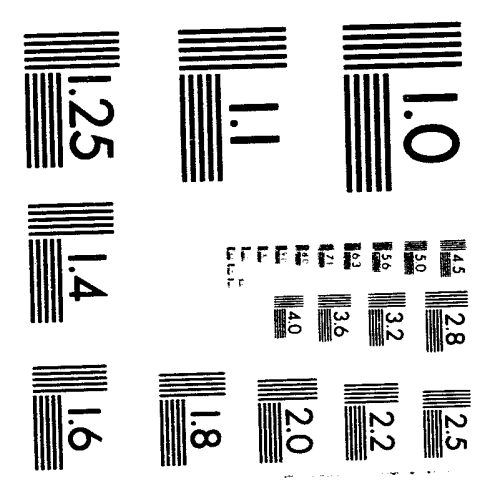



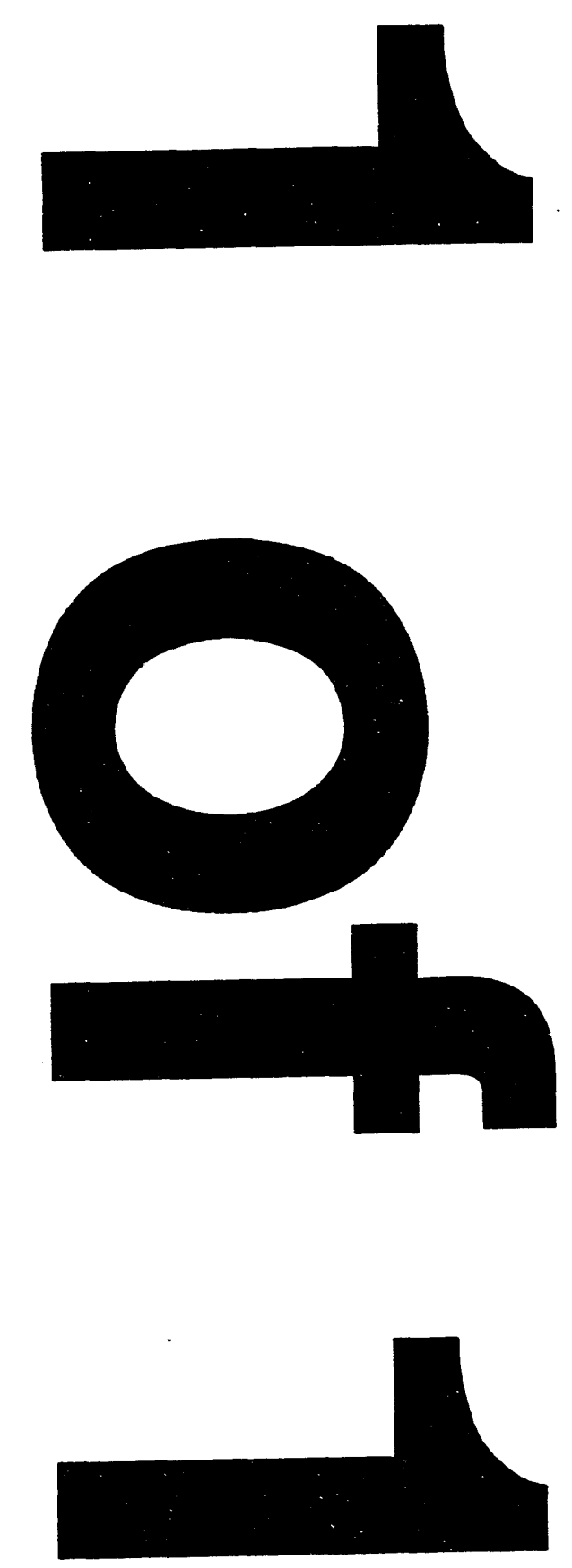
SAND94-8524

Unlimited Release

January 1994

\title{
THE DECOMPOSITION OF METHYLTRICHLOROSILANE: STUDIES IN A HIGH-TEMPERATURE FLOW REACTOR*
}

\author{
MARK D. ALLENDORF, THOMAS H. OSTERHELD, and CARL F. MELIUS \\ Combustion Research Facility \\ Sandia National Laboratories \\ Mail Stop 9052 \\ Livermore, CA 94551-0969
}

\begin{abstract}
Experimental measurements of the decomposition of methyltrichlorosilane (MTS), a common silicon carbide precursor, in a high-temperature flow reactor are presented. The results indicate that methane and hydrogen chloride are major products of the decomposition. No chlorinated silane products were observed. Hydrogen carrier gas was found to increase the rate of MTS decomposition. The observations suggest a radical-chain mechanism for the decomposition. The implications for silicon carbide chemical vapor deposition are discussed.
\end{abstract}

\section{MASTER}

*This work was supported by the Advanced Industrial Materials Program of the U.S. Dept. of Energy Office of Industrial Technologies.

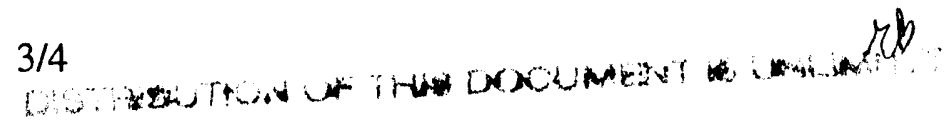




\section{INTRODUCTION}

Methyltrichlorosilane (MTS) is commonly used in chemical vapor infiltration processes as a precursor to silicon carbide $(\mathrm{SiC})[1,2]$ Its use is also being explored for the production of thin films for electronics applications [3]. The kinetics of SiC chemical vapor deposition from MTS have been of interest for some time, since computational models are needed to assist in the optimization and scale-up of new synthetic methods. Unfortunately, little is known about the high-temperature reactions of chlorinated organosilanes. In a widely cited paper, Burgess and Lewis measured the MTS pyrolysis rate in hydrogen at atmospheric pressure [4]. Later, Davidson and Dean attempted to measure the unimolecular pyrolysis rates for a series of chlorinated methylsilanes (not including MTS), but found it difficult to achieve non-chain conditions for these systems [5]. Most recently, Niiranen and Gutman measured the $\mathrm{SiCl}_{3}+\mathrm{CH}_{3}$ recombination rate at $300 \mathrm{~K}$ and 2 torr using photoionization mass spectrometry [6]. The limited information relevant to MTS available from these studies indicates that additional experimental data are needed to fully understand the decomposition chemistry of this precursor.

In this paper, we describe measurements of MTS decomposition conducted in a hightemperature flow reactor (HTFR) using a mass spectrometer to monitor the course of reaction. The objectives are: 1) to identify the products of MTS decomposition, 2) to determine the effects of different carrier gases on the decomposition, and 3) to suggest a mechanism for pyrolysis. Following a description of the experimental procedures used, a brief discussion of earlier theoretical predictions is presented to provide useful background for understanding the experimental results.

\section{EXPERIMENTAL METHODS}

A schematic view of the HTFR uried in these experiments is shown in Figure 1. Reactions occur within a graphite tube with an ID of $5.0 \mathrm{~cm}$ and a length of $100 \mathrm{~cm}$. The tube is enclosed in a water-cooled, insulated vacuum chamber. Three independently controlled heating elements surround the tube and can heat the gases flowing within it up to $1500 \mathrm{~K}$. Reactor pressure is controlled by a pressure transducer coupled to a throttle valve in the vacuum line. In a typical experiment, carrier gas (hydrogen or helium) enters the reactor tube at the top and is preheated to the reaction temperature by the first heating element. MTS is then added to the hot carrier gas through a movable, water-cooled injector, allowing its residence time to be varied (from zero to $100 \mathrm{msec}$ in these experiments, based on the average flow velocity). The residence time of the MTS is then varied with respect to a mass spectrometer probe located at the center of the interaction region, defined by the intersection of the window ports. The following HTFR conditions were used: total reactor pressure, $25.0 \pm 0.2$ torr; reactor temperature, $1243 \pm 10 \mathrm{~K}$; total flow rate, $5.00 \mathrm{slpm}$; MTS flow rate, $50 \mathrm{sccm}$.

MTS and its decomposition products were detected by an Extrel EXM-500 quadrupole mass spectrometer using electron impact ionization. Masses up to 500 amu and species concentrations as low as $5 \mathrm{ppm}$ (based on detection of $38 \mathrm{Ar}$ in air) are observaule with this instrument. Gases are extracted from the HTFR by a quartz sampling probe with a $475-\mu \mathrm{m}$ orifice inserted into the center of the flow in the diagnostic region. The pressure inside the probe 
is maintained at 1.00 torr by a pressure transducer/throttle valve combination. Since the probe pressure is typically a factor of 10 or more lower than the pressure within the HTFR, the rates of chemical reactions (in particular, radical-radical reactions) within the probe are substantially reduced. After extraction, the sampled gases flow past a $200-\mu \mathrm{m}$ orifice attached to the mass spectrometer chamber. The small amount of the gases leaking through the orifice forms a molecular beam, which is then ionized and detected by the spectrometer.

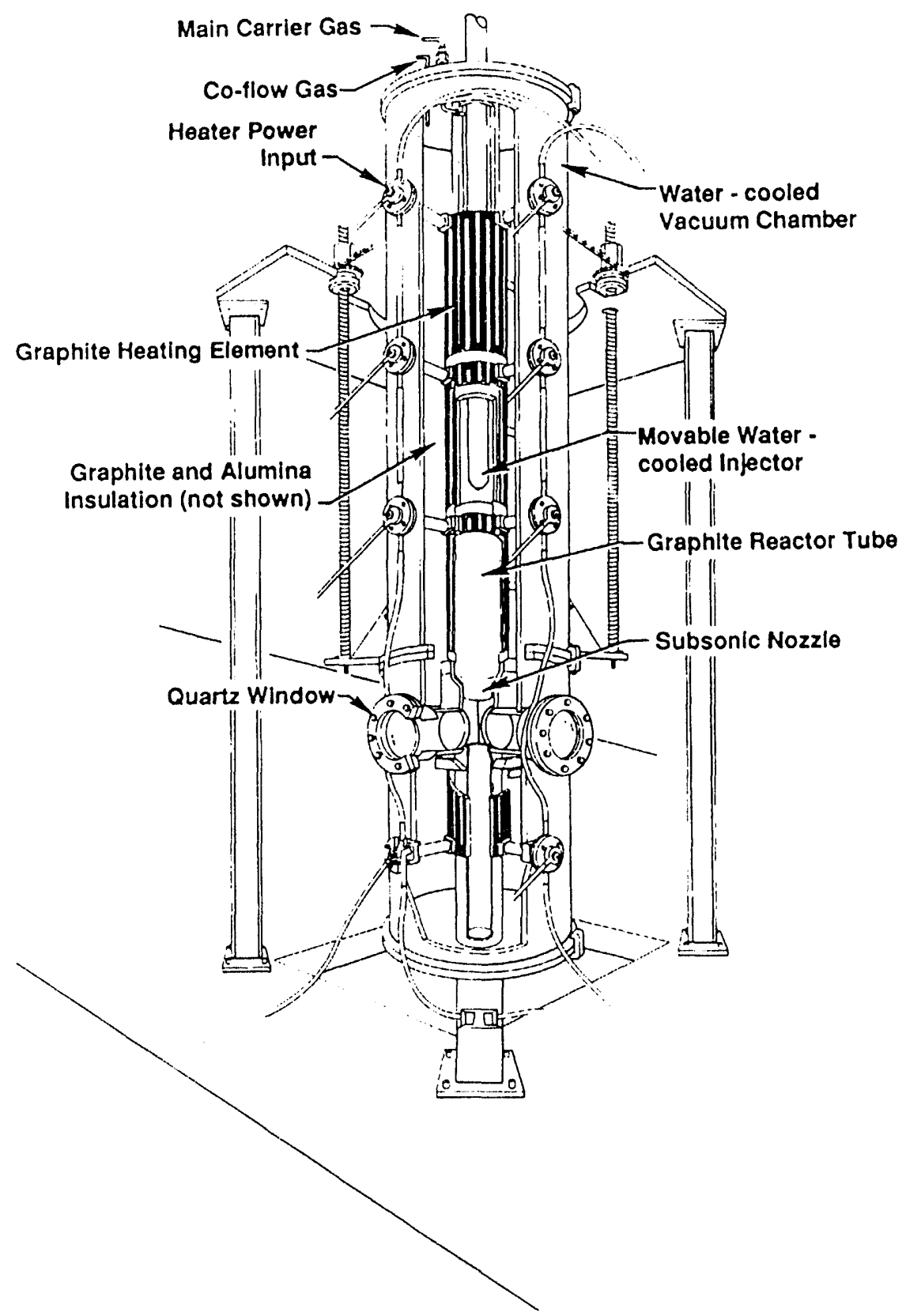

Figure 1: Schematic view of the high-temperature flow reactor. 


\section{THEORETICAL PREDICTIONS OF MTS PYROLYSIS}

The experiments described here provide an opportunity to test some of the predictions of our earlier theoretical analyses of MTS pyrolysis, in which we describe both the reaction thermochemistry [7] and kinetics [8]. To estimate MTS decomposition rates as a function of temperature and pressure, transition state (RRKM) theory was employed to predict rates for several unimolecular MTS decomposition pathways [8], using transition state structures obtained from ab initio electronic structure calculations [7]. These calculations indicate that the three most important decomposition pathways are:

$$
\begin{aligned}
& \mathrm{CH}_{3} \mathrm{SiCl}_{3}+\mathrm{M} \rightarrow \mathrm{CH}_{3}+\mathrm{SiCl}_{3}+\mathrm{M} \\
& \mathrm{CH}_{3} \mathrm{SiCl}_{3}+\mathrm{M} \rightarrow \mathrm{CH}_{2} \mathrm{SiCl}_{3}+\mathrm{H}+\mathrm{M} \\
& \mathrm{CH}_{3} \mathrm{SiCl}_{3}+\mathrm{M} \rightarrow \mathrm{CH}_{2}=\mathrm{SiCl}_{2}+\mathrm{HCl}+\mathrm{M}
\end{aligned}
$$

At the temperatures and pressures typical of SiC CVD (1300 - $1500 \mathrm{~K}, 10-760$ torr), the rate of Reaction (1) exceeds that of the other two by at least two orders of magnitude. This is illustrated in Figure 2 for the case of hydrogen carrier gas at $1300 \mathrm{~K}$. Exchanging hydrogen for helium increases the rates of Reactions (2) and (3) relative to Reaction (1), but the rate of Reaction (1) still exceeds that of the other two by at least a factor of 65 .

A second prediction of these calculations is that substitution of hydrogen for helium as the carrier gas will decrease the total MTS decomposition rate by about a factor of two, due to the less effective collisional energy transfer expected from hydrogen. A final important finding is that all three reaction channels are sensitive to the total pressure, as illustrated in Figure 2. Decreasing the hydrogen carrier gas pressure from 760 torr to 10 torr results in a factor of 13 decrease in the total MTS decomposition rate.

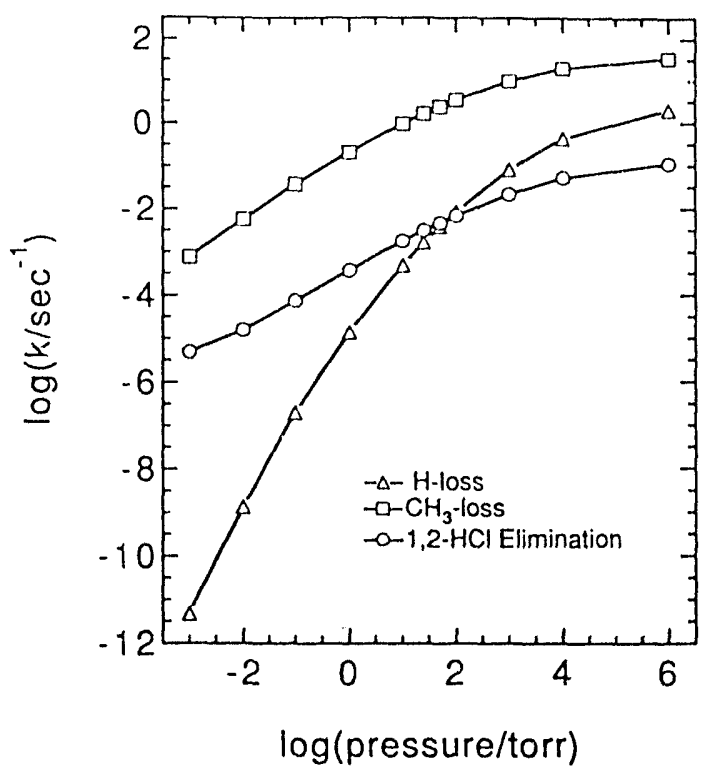

Figure 2: Pressure dependence of the three major MTS unimolecular decomposition pathways. 


\section{EXPERIMENTAL RESULTS AND DISCUSSION}

Experiments in the H'TFR using mass spectrometric detection identified two products of MTS decomposition. The results of these experiments are shown in Figures 3 and 4. Figure 3 shows the mass spectrum obtained for a mixture of $1 \%$ MTS in helium with a residence time in the heated zone of $82 \mathrm{msec}$. Peaks due to background gases were partially removed by subtracting the spectrum obtained in the absence of MTS. Peaks at $\mathrm{m} / \mathrm{z}$ (mass/charge) ratios of $148,133,113,98,76$, and 63 correspond to the $\mathrm{CH}_{3} \mathrm{SiCl}_{3}{ }^{+}, \mathrm{SiCl}_{3}{ }^{+}, \mathrm{CH}_{3} \mathrm{SiCl}_{2}{ }^{+}, \mathrm{SiCl}_{2}{ }^{+}$, $\mathrm{CHSiCl}^{+}$, and $\mathrm{SiCl}^{+}$ions produced by fragmentation of $\mathrm{MTS}$ in the spectrometer (smaller peaks 2-6 mass units above each of these correspond to fragments containing the ${ }^{37} \mathrm{Cl}$ isotope). Also apparent in this spectrum are peaks at $\mathrm{m} / \mathrm{z}=36$ and 38 , corresponding to the two isotopic forms of $\mathrm{HCl}$; this identifies $\mathrm{HCl}$ as an $\mathrm{MTS}$ decomposition product. Peaks in the range $\mathrm{of} \mathrm{m} / \mathrm{z}$ values between 12 and 30, where hydrocarbon fragments are expected to appear, cannot be readily identified since accurate baseline subtraction is difficult to achieve (often producing negative peaks, for example) due to overlap with much larger background peaks.

Notably absent in Figure 3 are peaks associated with chlorosilanes other than MTS, which could form as the result of secondary reactions occuring after Reactions 1-3. No signal was observed at $\mathrm{m} / \mathrm{z}$ values corresponding to $\mathrm{SiCl}_{4}$ or $\mathrm{HSiCl}_{3}$ (the parent ion of $\mathrm{SiH}_{2} \mathrm{Cl}_{2}$ cannot be conclusively identified due to its overlap with the ${ }^{28} \mathrm{Si}^{37} \mathrm{Cl}^{35} \mathrm{Cl}$ peak at $\left.\mathrm{m} / \mathrm{z}=100\right)$. A compolind that would be formed by the reaction of two $\mathrm{CH}_{2} \mathrm{SiCl}_{3}$ molecules from Reaction (2), $\mathrm{Cl}_{3} \mathrm{SiCH}_{2} \mathrm{CH}_{2} \mathrm{SiCl}_{3}(\mathrm{~m} / \mathrm{z}=294)$, also could not be detected. The absence of signal at these $\mathrm{m} / \mathrm{z}$ values suggests that silicon-containing radicals formed in the initial stages of MTS decomposition are lost to the reactor or probe walls before reaching the spectrometer. If this is occuring, it may be possible to reduce the rate of wall loss by converting the radical to a more stable species by reacting it with a trapping agent. In the case of $\mathrm{MTS}$ decomposition, $\mathrm{SiCl}_{3}$ molecules formed by Reaction (1) are expected to further decompose via the reaction $\mathrm{SiCl}_{3} \rightarrow$ $\mathrm{SiCl}_{2}+\mathrm{Cl}$. Since silylenes such as $\mathrm{SiCl}_{2}$ are known to react with unsaturated hydrocarbons to form stable alkylsilanes [9], we attempted to trap these molecules by adding $\mathrm{C}_{2} \mathrm{H}_{4}$ to the carrier gas. The compound that would be formed is $\mathrm{HCl}_{2} \mathrm{SiCH}=\mathrm{CH}_{2}$, giving mass peaks at $\mathrm{m} / \mathrm{z}=126$, 99, and 91 corresponding to the fragments $\mathrm{HCl}_{2} \mathrm{SiCH}=\mathrm{CH}_{2}{ }^{+}, \mathrm{SiCl}_{2} \mathrm{H}^{+}$, and $\mathrm{HClSiCH}=\mathrm{CH}_{2}{ }^{+}$. Efforts to detect these fragments in both helium and hydrogen carrier gas were unsuccessful. This suggests that the $\mathrm{SiCl}_{2}$ molecule, if it forms, is also lost to the walls or that the addition product is not sufficiently stable to be detected.

In addition to $\mathrm{HCl}$, a second product of MTS decomposition was detected by monitoring the signal at $\mathrm{m} / \mathrm{z}=15$, which corresponds to the $\mathrm{CH}_{3}+$ fragment. As discussed earlier, interference from background gases complicates data collection in the 12-30 amu region. Meaningful data can be obtained, however, by averaging the signal at a particular mass over a period of one to two minutes. Data obtained in this manner are presented in Figure 4, which shows the intensity of the $m / z=133$ and $m / z=15$ peaks as a function of reactor residence time. 


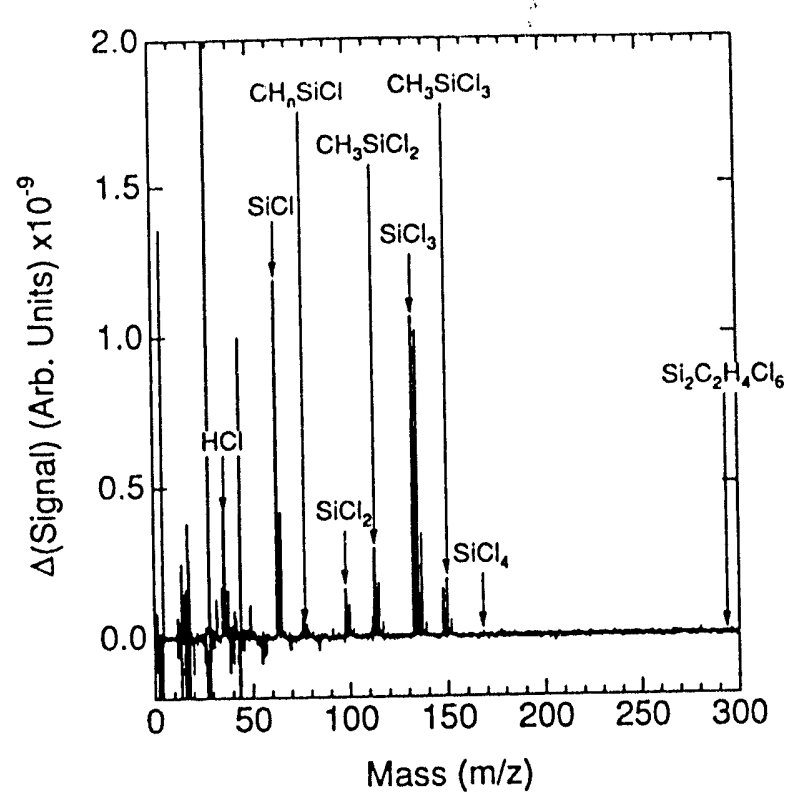

Figure 3: Mass spectrum (backgroundsubstracted) of MTS in helium at 25.0 torr and $1243 \mathrm{~K}$, showing the presence of $\mathrm{HCl}$ as a product and the absence of chlorosilanes $\mathrm{SiCl}_{4}$ and $\mathrm{Cl}_{3} \mathrm{SiCH}_{2} \mathrm{CH}_{2} \mathrm{SiCl}_{3}$ (labelled $\mathrm{Si}_{2} \mathrm{C}_{2} \mathrm{H}_{4} \mathrm{Cl}_{6}$ in the figure) as products.

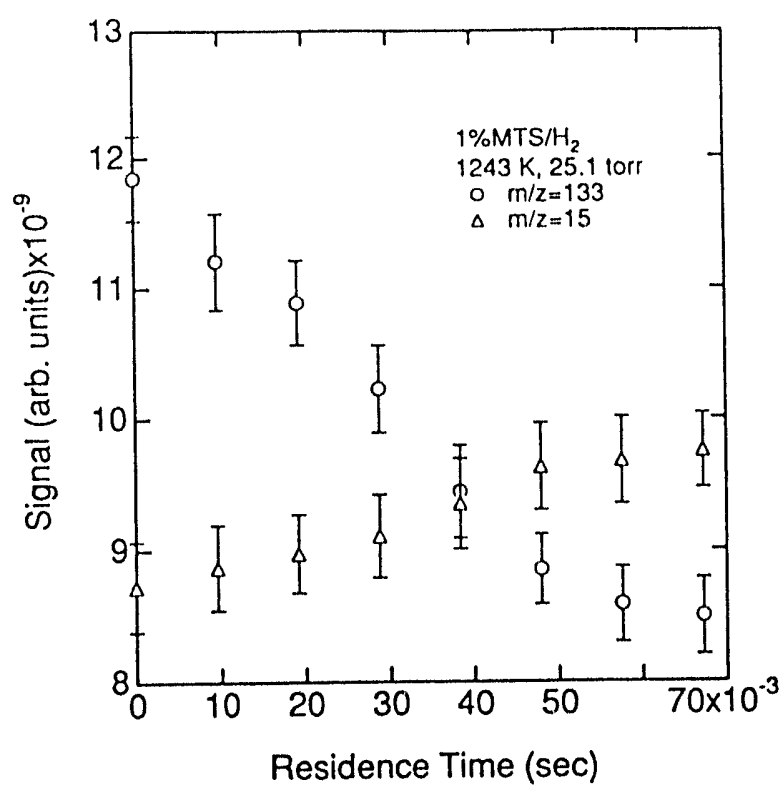

Figure 4: Signal-averaged data for $\mathrm{m} / \mathrm{z}=15$ $\left(\mathrm{CH}_{3}{ }^{+}\right.$; corresponds to $\left.\mathrm{CH}_{4}\right)$ and $\mathrm{m} / \mathrm{z}=133$ $\left(\mathrm{SiCl}_{3}{ }^{+}\right.$; corresponds to $\mathrm{MTS}$ ) versus reactor residence time, showing that $\mathrm{CH}_{4}$ is produced as MTS decomposes. Data for each mass averaged over 3.5 minutes.

The concentration of MTS decreases as the residence time increases, showing that MTS is decomposing in the reactor. Simultaneously, the $\mathrm{m} / \mathrm{z}=15$ peak increases with increasing residence time, indicating that the parent compound is a product of the pyrolysis reaction. The likely source of this signal is methane; plots of the signals at $\mathrm{m} / \mathrm{z}$ values corresponding to ethane (which could form by recombination of $\mathrm{CH}_{3}$ radicals) show no such increase. Similar behavior is obtained at $\mathrm{m} / \mathrm{z}=16$ (corresponding to $\mathrm{CH}_{4}{ }^{+}$), but with reduced precision due to overlap with the very strong $\mathrm{O}^{+}$peak. The detection of $\mathrm{CH}_{4}$ indicates that some of the MTS decomposes via Reaction (1). Quantitative experiments correlating the concentration of MTS and $\mathrm{CH}_{4}$ are now required to determine if Reaction (1) is the primary decomposition channel.

The effect of exchanging helium for hydrogen carrier gas on the overall MTS decomposition rate was also examined. As discussed above, the unimolecular decomposition Reactions 1-3 are predicted to be a factor of two slower in hydrogen than in helium. Figure 5 compares the amount of MTS decomposition observed in helium versus hydrogen, as indicated by the change in the $\mathrm{m} / \mathrm{z}$ peaks corresponding to the $\mathrm{SiCl}_{3}+$ cracking fragment of MTS. In helium, $\mathrm{m} / \mathrm{z}=133$ decreases by about $5 \%$ for an MTS residence time of $67 \mathrm{msec}$. In hydrogen, however, the decrease is much larger, about $17 \%$ for the same residence time. Thus, addition of hydrogen increases the MTS decomposition rate. Since this is the opposite effect of that predicted by collisional energy transfer arguments [8], an additional NiTS decomposition mechanism must be operative that is accelerated by the addition of hydrogen. 

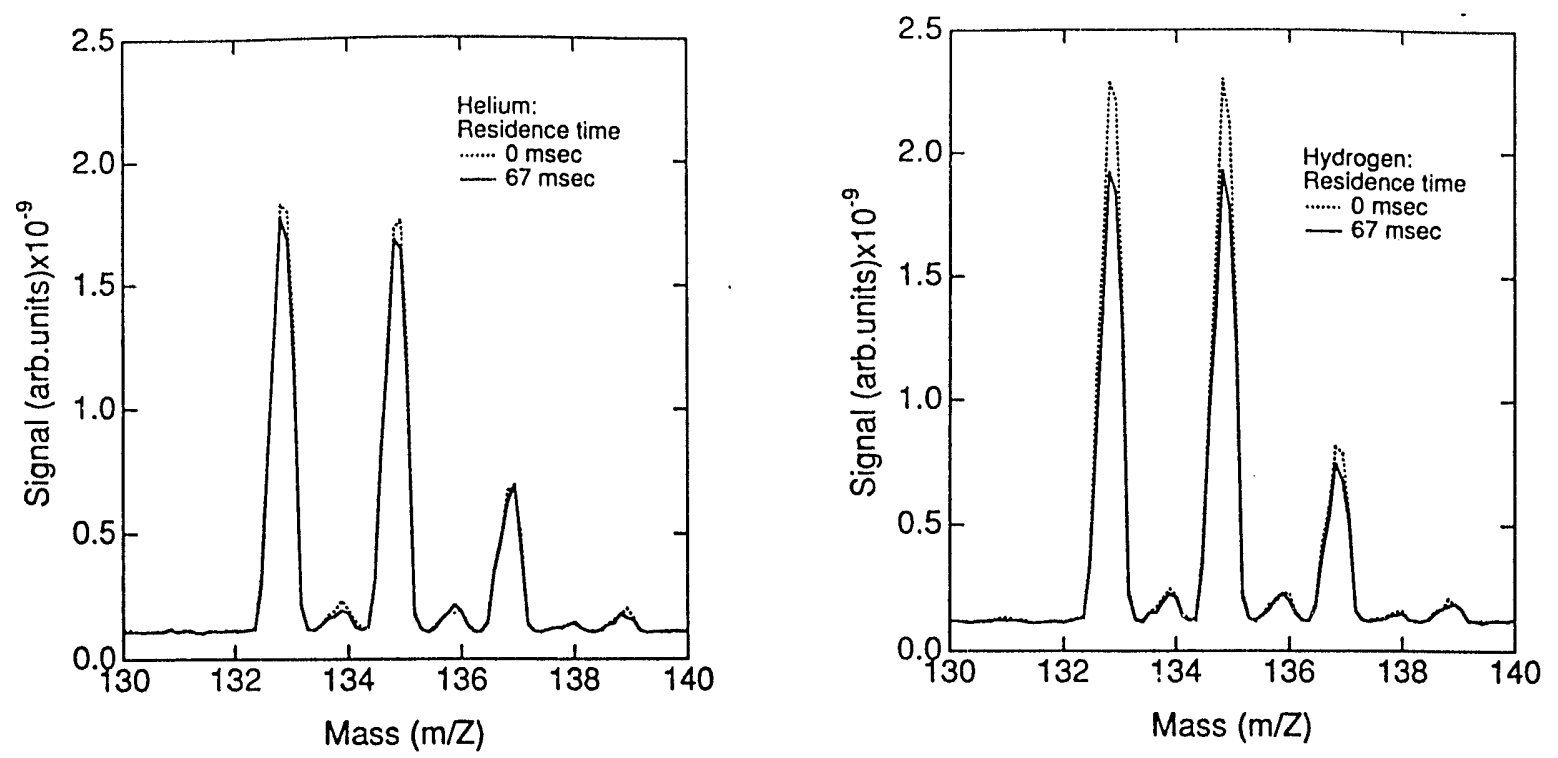

Figure 5: Comparison of mass spectrometer peaks corresponding to $\mathrm{SiCl}_{3}+$ ions for helium versus hydrogen carrier gas at $1243 \mathrm{~K}, 25$ torr.

The observations described above are consistent with a radical-chain mechanism in which hydrogen atoms and methyl radicals play an important role. Such mechanisms have been proposed for other chlorosilanes [5]. The mechanism is described by the following reactions:

Initiation: $\quad \mathrm{CH}_{3} \mathrm{SiCl}_{3}+\mathrm{M} \rightarrow \mathrm{CH}_{3}+\mathrm{SiCl}_{3}+\mathrm{M}$

Chain Propagation: $\quad \mathrm{CH}_{3} \mathrm{SiCl}_{3}+\mathrm{CH}_{3} \rightarrow \mathrm{CH}_{4}+\mathrm{CH}_{2} \mathrm{SiCl}_{3}$

$\mathrm{CH}_{3}+\mathrm{H}_{2} \rightarrow \mathrm{CH}_{4}+\mathrm{H}$

$\mathrm{H}+\mathrm{CH}_{3} \mathrm{SiCl}_{3} \rightarrow \mathrm{H}_{2}+\mathrm{CH}_{2} \mathrm{SiCl}_{3}$

$\mathrm{SiCl}_{3} \rightarrow \mathrm{SiCl}_{2}+\mathrm{Cl}$

$\mathrm{Cl}+\mathrm{CH}_{3} \mathrm{SiCl}_{3} \rightarrow \mathrm{HCl}+\mathrm{CH}_{2} \mathrm{SiCl}_{3}$

$\mathrm{Cl}+\mathrm{H}_{2} \rightarrow \mathrm{HCl}+\mathrm{H}$

Chain Termination: $\quad \mathrm{SiCl}_{3}+$ wall $\rightarrow \mathrm{SiCl}_{3}(\mathrm{w})$

$\mathrm{SiCl}_{2}+$ wall $\rightarrow \mathrm{SiCl}_{2}(\mathrm{w})$

$\mathrm{CH}_{2} \mathrm{SiCl}_{3}+$ wall $\rightarrow \mathrm{CH}_{2} \mathrm{SiCl}_{3}(\mathrm{w})$

$\mathrm{H}+\mathrm{H}+\mathrm{M} \rightarrow \mathrm{H}_{2}+\mathrm{M}$

$\mathrm{H}+\mathrm{Cl}+\mathrm{M} \rightarrow \mathrm{HCl}+\mathrm{M}$

$\mathrm{CH}_{3}+\mathrm{H}+\mathrm{M} \rightarrow \mathrm{CH}_{4}+\mathrm{M}$

As predicted by the RRKM calculations, the initation step in this mechanism is the breaking of the Si-C bond. The methyl radical formed in this step can then react with another MTS molecule to produce methane, thereby accounting for the observed production of this species in helium carrier gas. Exchanging hydrogen for helium as the carrier gas accelerates the conversion of the methyl radical to methane by providing a second, presumably faster, pathway 
(Reaction 5). Since Reaction 5 also produces an $\mathrm{H}$ atom, the MTS decomposition rate also increases via Reaction 6.

Formation of $\mathrm{HCl}$ occurs through Reactions 7-9. Since the $\mathrm{Si}-\mathrm{Cl}$ bond strength [7] in $\mathrm{SiCl}_{3}$ is only $68.8 \mathrm{kcal} \mathrm{mol}^{-1}$, thermal energy sufficient to frasment the $\mathrm{Si}-\mathrm{C}$ bond (whose strength is $96.7 \mathrm{kcal} \mathrm{mol}^{-1}$ ) is easily sufficient to drive Reaction 7. Other pathways leading to $\mathrm{Cl}$ atom formation, such as breaking the $\mathrm{Si}-\mathrm{Cl}$ bond in MTS, or elimination of $\mathrm{HCl}$ via Reaction 3, are expected to be significantly slower than Reaction 7 .

The lack of chlorosilane products is accounted for in the mechanism by wall-loss, Reactions 10-12. Although these experiments provide no direct evidence of this, measurements of $\mathrm{SiCl}_{3}$ wall-loss rates at room temperature by Niiranen and Gutman indicate that Reaction 10 at least should be very fast [6]. They obtained a wall-loss rate of $170 \mathrm{~s}^{-1}$ for Reaction 10; for comparison, the rate of Reaction 1 is predicted by RRKM calculations to be about $1 \mathrm{~s}^{-1}$ in helium at 25 torr and $1243 \mathrm{~K}$.

The mechanism suggested above has significant consequences for SiC CVD. First, the observed activation energy for MTS pyrolysis will be substantially lower than that predicted by RRKM theory, since the chain-propagation reactions (4)-(6) have very low activation energies $\left(8-10 \mathrm{kcal} \mathrm{mol}^{-1}\right)$ compared with the much higher activation energies associated with initiation (>75 kcal mol $\mathrm{k}^{-1}$ at 25 torr). Thus, MTS decomposition will proceed at reactor temperatures lower than those expected from a purely unimolecular, non-chain process. Second, the rapid loss of silicon-containing species to the walls implied by Reactions (10)-(12) is consistent with the suggestion of previous investigators, namely, that incorporation of silicon during SiC CVD is rapid and the process is limited by the reaction of stable hydrocarbons with the surface [10]. Finally, the identification of methane as the principal carbon-containing product suggests that carbon deposition may be slow, since the reactivity of methane with the silicon carbide surface appears to be low [11].

In summary, the results presented here provide a qualitative picture of MTS decomposition, identifying some of the gas-phase products and suggesting a mechanism for the pyrolysis of MTS at CVD temperatures. Additional data are required to provide quantitative information on the rates of wall reactions, homogeneous decomposition rates, and the effects of temperature and pressure. Experiments to obtain this information are now underway.

\section{REFERENCES}

1. J. Schlichting, Powder Metal. Inter. 12, 196 (1980).

2. T. M. Besmann, B. N. Gallois, J. W. Warren, Eds., Chemical Vapor Deposition of Refractory Metals and Ceramics II (Mater. Res. Soc. Proc. 250, Pittsburgh, PA, 1992).

3. C. C. Chiu, S. B. Desu, C. Y. Tsai, J. Mater. Res. 8, 2617 (1993).

4. J. N. Burgess, T. J. Lewis, Chemistry and Industry, 76 (1974).

5. I. M. T. Davidson, C. E. Dean, Organometallics 6, 966 (1987).

6. J. T. Niiranen, D. Gutman, J. Phys. Chem. 97, 9392 (1993).

7. M. D. Allendorf, C. F. Melius, J. Phys. Chem. 97, 720 (1993). 
8. T. H. Osterheld, M. D. Allendorf, C. F. Melius, submitted to J. Phys. Chem., 1993.

9. I. Safarik, B. P. Ruzsicska, A. Jodhan, O. P. Strausz, Chem. Phys. Lett. 113, 71 (1985).

10. G. S. Fischman, W. T. Petuskey, J. Am. Ceram. Soc. 68, 185 (1985).

11. C. D. Stinespring, J. C. Wormhoudt, J. Appl. Phys. 65, 1733 (1989). 


\section{INITIAL DISTRIBUTION}

UNLIMITED RELEASE

Dr. Peter Angelini

Bldg. 4515

Oak Ridge National Laboratories

P.O. Box 2008, 1 Bethel Valley Road

Oak Ridge, TN 37831-6065

Dr. Charles A. Sorrell

Adv. Industrial Concepts Div., CE-232

U.S. DOE - CE

Forrestal Building, 1000 Independence Ave.

Washington, DC 20585

Dr. K.B. Alexander

Metals and Ceramics Division

Oak Ridge National Laboratory

P.O. Box 2008

Oak Ridge, TN 37831-6068

Dr. Theodore M. Besmann

Oak Ridge National Laboratories

P.O. Box 2008

Oak Ridge, TN 37831-6063

Dr. R.P. Currier

C348

Los Alamos National Laboratory

P.O. Box 1663

Los Alamos, NM 87545

Dr. D.J. Devlin

K762

Los Alamos National Laboratory

P.O. Box 1663

Los Alamos, NM 87545

Dr. Greg Glaitzmaier

NREL

1617 Cole Blvd.

Golden, CO 80401

Dr. Suleyman A. Gokoglu

NASA Lewis Research Center

Mail Stop 106-1

Cleveland, $\mathrm{OH} 44135$

Dr. Michael Zachariah

National Institute of Standards of

Technology

Building 221, Rm. B312

Gaithersburg, MD 20899
Prof. C. Bernard

Laboratoire de Thermodynamique

ENSEEG

BP.75,38402

St. Martin d'Heres

France

Prof. Jan-Otto Carlsson

Uppsala University

Chemistry Department

Box 531

S-75121 Uppsala

Sweden

Professor Seshu B. Desu

Department of Materials Science

and Engineering

Virginia Polytechnic Institute

213 Holden Hall

Blacksburg, VA 24061-0140

Prof. James Edgar

Department of Chemical Engineering

Kansas State University

Manhattan, KS 66506-5102

Prof. James W. Evans

Dept. of Materials Science

and Mineral Engineering

University of California

Berkeley, CA 94720

Prof. Bernard Gallois

Dept. of Materials Science

Stevens Institute of Technology

Castle Point on the Hudson

Hoboken, NJ 07030

Prof. David Gutman

Department of Chemistry

Catholic University of America

Washington, DC 20064

Prof. M.C. Lin

Department of Chemistry

Emory University

Atlanta, GA 30322

Prof. Paul Marshall

Department of Chemistry

University of North Texas

P.O. Box 5068

Denton, TX 76203-5068 
Prof. Triantafillos J. Mountziaris

Chemical Engineering Dept.

SUNY Buffalo

Buffalo, NY 14260

Dr. Roger Naslain

Laboratorie des Composites

Thermostructuraux

Domaine Universitaire

33600 Pessac

France

Prof. H. Edward O'Neal

Department of Chemistry

San Diego State University

San Diego, CA 92182-0328

Dr. Daniel J. Skamser

Dept. of Materials Science and Engineering

Northwestern University

MLSF 2036

Evanston, IL 60208-3108

Prof. Karl E. Spear

Dept. of Ceramic Science and Engineering

Pennsylvania State University

201 Steidle Building

University Park, PA 16802

Prof. Thomas L. Starr

Room 113

Baker Building

Georgia Institute of Technology

Atlanta, GA 30332-0245

Professor Stan Veprek

Institute of Chemistry of

Information Recording

Technical University of Munich

Lichtenbergstrasse 4

D-8046 Barching-Munich

Germany

Dr. H.F. Calcote

Director of Research

Aerochem Research Laboratories

P.O. Box 1

Princeton, NJ 08542

Dr. Jitendra S. Goela

Morton Advanced Materials

185 New Boston Street

Woburn, MA 01801-6278
Prof. H. Komiyama

Department of Chemical Engineering

University of Tokyo

Hongo 7, Bunkyo-ku

Tokyo 113

Japan

Dr. F. Langlais

Laboratoire des Composities

Thermostructuraux

Domaine Universitaire

33600 Pessac

France

Dr. John A. Mucha

Room 1D-357

AT\&T Bell Laboratories

600 Mountain Avenue

Murrya Hill, NJ 07974-2070

Mr. Peter Reagan

Project Manager, CVD Composites

Thermo Trex Corporation

74 West Street, P.O. Box 9046

Waltham, MA 02254-9046

Prof. Daniel E. Rosner

Chemical Engineering Dept.

Yale University

P.O. Box 2159, Yale Station

New Haven, CT 06520-2159

Dr. Andrew J. Sherman

Ultramet

12173 Montague Street

Pacoima, CA 91331

Dr. Richard Silberglitt

Technology Assessment and Transfer, Inc.

133 Defense Highway, \#212

Annapolis, MD 21401

Dr. Richard G. Tave

Day and Zimmerman, Inc.

1818 Market Street

Philidelphia, PA 19103

MS0350 S.T. Picraux, 1112

MS0601 M.E. Coltrin, 1126

MS0601 P. Ho, 1126 
MS0336 R.J. Eagan, 1700

Attn: D.W. Schaefer, 1703

R.E. Loehman, 1708

MS0735 D.E. Arvizu, 6200

MS0710 G.A. Carlson, 6211

MS9001 J.C. Crawford, 8000

Attn: E.E. Ives, 8100

R.J. Detry, 8200

MS9053 T.T. Bramlette, 8106

MS9054 W.J. McLean, 8300

Attn: W. Bauer, 8302

W.G. Wolfer, 8341

R.H. Stulen, 8342

A. Pontau, 8347

G.A. Fisk, 8355

R.W. Carling, 8362

C. Hartwig, 8366

MS9054 D.L. Lindner, 8300A

MS9162 D.A. Outka, 8347

MS9214 C.F. Melius, 8353

MS9052 M.D. Allendorf, 8361 (10)

MS90.52 D.R. Hardesty, 8361 (5)

Attn: L.L. Baxter

K.A. Davis

R.H. Hurt

J.O. Keller

S.F. Rice

R.R. Steeper

MS9401 R.C. Wayne, 8700

Attn: C.W. Robinson, 8702

M.I. Baskes, 8712

J.M. Hruby, 8713

M.C. Nichols, 8713

M.W. Perra, 8714

R.E. Stoltz, 8716

MS904.3 R.J. Kee, 8745

Attn: W.G. Houf

R.S. Larson

E. Meeks
MS9021 Publications for OSTI, 8535 (10)

MS9021 Publications/Technical Library Processes, 8.535

MS0899 Technical Library Processes, 7141 (4)

MS9017 Central Technical Files, 8523-2 (3) 

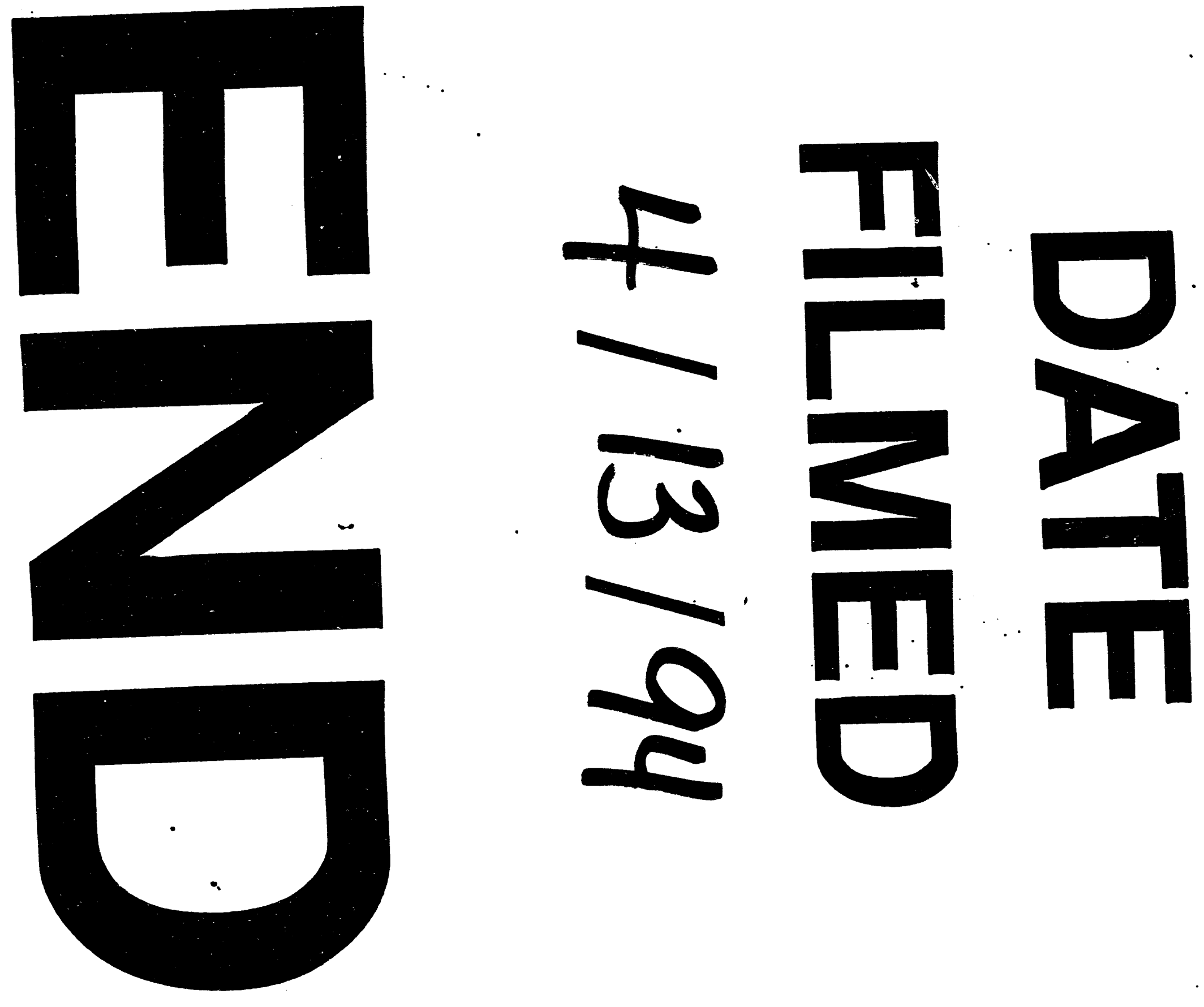
